\title{
Rolling and recrystallization behavior of pure zirconium and zircaloy-4
}

\author{
${ }^{1}$ Universidade Tecnológica Federal do Paraná - Campus Londrina, Estrada dos Pioneiros, 3131 - Jardim Morumbi, CEP \\ 86036-370, Londrina, Paraná, Brasil. \\ e-mail: azimmermann@utfpr.edu.br \\ ${ }^{2}$ Departamento de Engenharia Metalúrgica e de Materiais, Escola Politécnica, Universidade de São Paulo - USP, Av. \\ Professor Mello Moraes, 2463, CEP 05508-930, São Paulo, São Paulo, Brasil. \\ e-mail: padilha@usp.br
}

\begin{abstract}
Rolling and recrystallization of pure zirconium and zircaloy-4 have been studied comparatively in this paper. For the as-received condition, zirconium presented a recrystallized microstructure and the alloy a typical basketweave microstructure. Comparative rolling tests were performed, and reduction limit curves as a function of the rolling temperature were determined. At room temperature, pure $\mathrm{Zr}$ shows substantial plasticity and the alloy presents low ductility and many cracks. The ductility of both materials increases significantly with an increase in rolling temperature at the range between 300 and $500^{\circ} \mathrm{C}$. In static recrystallization studies, samples of the two materials with similar recrystallized grain size were cold-rolled with a thickness reduction of 55\%. During annealing, pure $\mathrm{Zr}$ and the alloy soften by recovery and recrystallization, however the relative contribution of recovery is lesser pronounced in the alloy, for which the recrystallization temperature increases by about $60^{\circ} \mathrm{C}$.
\end{abstract}

Keywords: Zirconium, zircaloy-4, rolling, recovery, recrystallization.

\section{INTRODUCTION}

Zirconium was isolated as a metal in 1824 and is the eighteenth most abundant element in the Earth's crust, more abundant than several popular metals, such as copper, nickel, zinc, lead, and niobium. The major application of metallic zirconium is in the nuclear industry, due to its low thermal neutron cross-section, very good aqueous corrosion resistance and enough strength at high temperature. For nuclear applications, hafnium must be removed, due to its extremely high absorption for thermal neutrons: almost 600 times larger than that of zirconium [1,2]. Reactor-grade zirconium containing less than $100 \mathrm{ppm}$ hafnium is frequently alloyed with tin, iron, chromium, and occasionally with nickel to improve mechanical properties and corrosion resistance in water and steam at high temperatures. These alloys, called zircaloys, are very often selected for fuel cladding, spacer grids and intermediate flow mixers for water cooled thermal nuclear reactors. Zircaloy4, containing 1.20-1.70 Sn, 0.18-0.24 Fe, and 0.07-1.30 wt\% Cr, is one of the most used zirconium alloys in nuclear technology $[3,4,5]$.

Pure zirconium shows outstanding corrosion resistance to most organic and mineral acids and is resistant to most inorganic salts. Unalloyed zirconium, which contains up to $4.5 \%$ hafnium, is called commercial-grade zirconium and is a usual choice in the chemical process industries $[1,6]$.

Fabrication of components of zirconium alloys and unalloyed zirconium used respectively in the nuclear and in the chemical industries invariably involves plastic deformation and annealing. Therefore, the knowledge of phenomena such as work-hardening, recovery and recrystallization is not only essential to the success of mechanical forming of components but also important to optimize the microstructure and properties of the finished products $[1,2,7]$.

There is extensive literature regarding plastic deformation, annealing behavior and crystallographic texture evolution of pure zirconium $[8,9,10]$ and zircaloy-4 $[11,12,13,14,15]$ published independently. However, comparative studies of both materials are scarce. Comparative studies could reveal relevant influences of alloying elements. Furthermore, numerous studies about zirconium employ commercial-grade zirconium 
$[16,17,18]$. The main objective of the present work is to compare the behavior of reactor-grade pure zirconium and zircaloy-4 during work-hardening, recovery and recrystallization.

\section{MATERIALS AND METHODS}

The starting materials were a plate of $5.5 \mathrm{~mm}$ thickness of pure zirconium and discs of $180 \mathrm{~mm}$ diameter and about $5.5 \mathrm{~mm}$ thickness of zircaloy-4. The materials were reactor-grade and the chemical composition of the alloy was: $0.10 \% \mathrm{Fe} ; 0.11 \% \mathrm{Cr} ; 1.45 \mathrm{wt} \% \mathrm{Sn}$. Both materials in the as-received condition were rolled at various temperatures, between room temperature and $600^{\circ} \mathrm{C}$ and then annealed for ductility and equalize the microstructures. Strips of recrystallized pure zirconium and zircaloy- 4 with similar grain size and dimensions were then cold rolled and annealed for static recrystallization studies. Each rolling pass was carried out alternating the strip surfaces (superior and inferior) to minimize sample curvature. No lubricant was used during rolling experiments.

The microstructures of samples were characterized by optical microscopy, scanning electron microscopy, hardness, electrical conductivity and crystallographic texture measurements. The metallographic sample preparation consisted of grinding (SiC abrasive paper 320, 600 and 1200 grit) and electrolytic polishing. For simultaneous polishing and etching of the samples, perchloric acid in methanol (1:10) was used, keeping the time of 20 seconds and adjusting the electric current to the sample size. Crystallographic textures of the materials in the rolled and recrystallized conditions were studied using pole figures and sections of Euler space of crystallographic orientation described by the ODF (Orientation Distribution Function), generated from these pole figures with the help of the MTEX computer program. An automatic texture goniometer coupled to a Rigaku diffractometer model DMAX-2000 was used. A copper K $\alpha$ radiation was used, with an angular step of $5^{\circ}$ and step counting time of 5 seconds. The crystallographic planes chosen to determinate the pole figures were: (002), (100) and (101). More details about the experiments and characterization of samples can be found elsewhere [19].

\section{RESULTS AND DISCUSSION}

In section 3.1, the characterization of the starting material (as-received condition) and of the samples that had equalized microstructure is presented, whereas in section 3.2 the recrystallization kinetics after cold rolling is discussed.

\subsection{The as-received condition and microstructure equalization}

In the as-received condition, pure zirconium (Zr) and zircaloy-4 (Zry-4) are monophasic ( $\alpha$-phase) but show completely diverse microstructures. While $\mathrm{Zr}$ shows equiaxed recrystallized grains, with an average diameter of about $50 \mu \mathrm{m}$, Zry-4 displays an entangled microstructure ("basketweave microstructure"), typical of zirconium alloys quenched from the $\beta$ phase (Figure 1), showing Widmannstätten plates growing from the former $\beta / \beta$ grain boundaries [2]. Crystallographic texture determinations of both materials were performed for several different material conditions. For the as-received condition, however, a comparative study between the two materials was not possible, since Zry-4 had a grain size too large to allow statistically significantly texture measurements. 


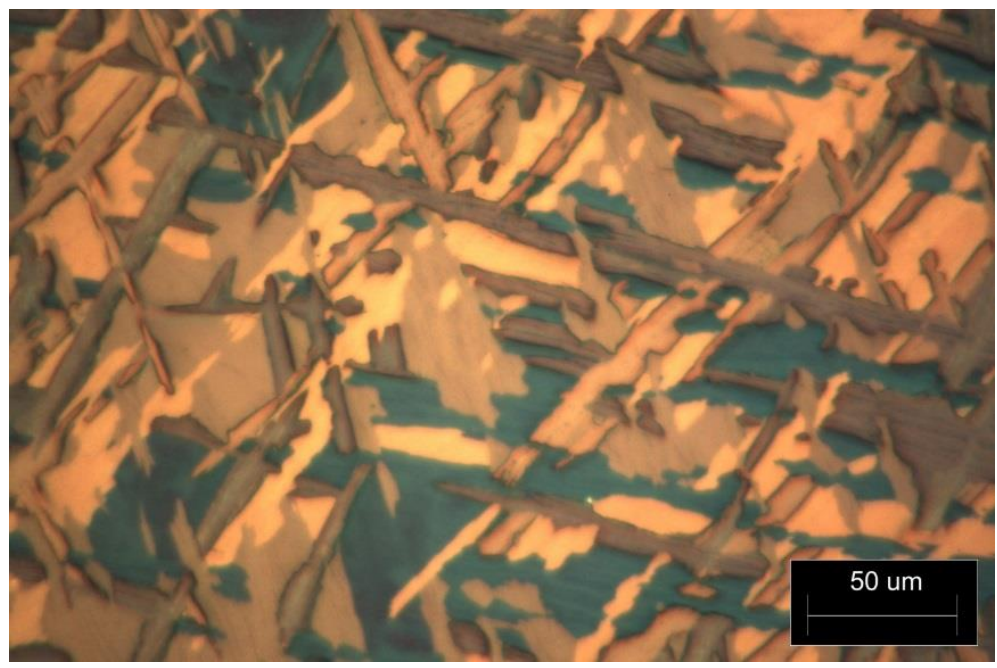

Figure 1: Optical micrograph using polarized light after electropolishing of zircaloy-4 in the as-received condition.

Both materials were plastically deformed and annealed to equalize their microstructures, resulting in equiaxed grains with similar average diameters, prior to the cold rolling and recrystallization experiments. For this purpose, rolling experiments and the determination of reduction limit curves without the presence of cracks as a function of temperature were conducted (see Figure 2). While pure Zr showed enough plasticity at room temperature, the alloy Zry-4 presented low ductility and many cracks. The ductility of both materials increased significantly with increasing rolling temperature above $300^{\circ} \mathrm{C}$ becoming virtually identical at $500^{\circ} \mathrm{C}$ (see Figure 2). According to the von Mises criteria, for a polycrystalline material to deform homogeneously without cracks, five independent slip systems are necessary. Metals with HCP crystalline structure in general and zirconium alloys in particular present difficulties to fulfill this requirement. Regardless of the deformation temperature, the prismatic slip is the dominant deformation mode in zirconium. New slip systems are activated when increasing the deformation temperature above $300^{\circ} \mathrm{C}$. The additional deformation modes are basal and pyramidal slip at high temperature and twinning at low temperature [20].

The crystallographic texture evolution during processing for both materials is summarized in Table 1. As a general trend, it can be stated that both $\mathrm{Zr}$ and Zry-4 presented strong resistance to texture changes during their mechanical and thermal processing.

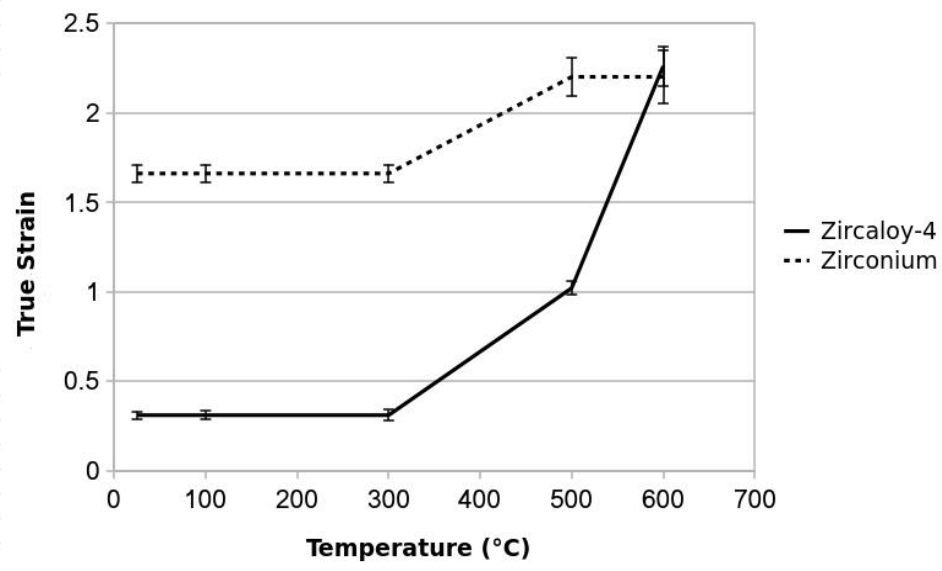

Figure 2: Reduction limit without the presence of macroscopic cracks in pure zirconium and zircaloy-4 stripes in the asreceived condition as a function of rolling temperature.

The crystallographic texture evolution during processing for both materials is summarized in Table 1. As a general trend, it can be stated that both pure $\mathrm{Zr}$ and Zry-4 presented strong resistance to texture shanmac during their mechanical and thermal processing. In pure $\mathrm{Zr}$, the texture component near $\{11 \overline{2} 2\}\langle 10 \overline{1} 0\rangle$ 
was fully developed after about 50\% thickness reduction, but was nearly unchanged thereafter, up to about $90 \%$ reduction. The texture was essentially the same up to a rollino temnernturs of $300^{\circ} \mathrm{C}$. After cold rolling, Zry-4 showed the predominance of a texture component near to $\{11 \overline{2} 2\}\langle 10 \overline{1} 0\rangle$. The texture changes that occurred in $\mathrm{Zr}$ and in Zry-4 at the rolling temperature of $600^{\circ} \mathrm{C}$ suggest the occurrence of recrystallization.

Table 1: Crystallographic texture of Zirconium and Zircaloy-4 in different conditions: as-received, rolled and annealed.

\begin{tabular}{|c|c|c|}
\hline SAMPLE CONDITION & ZIRCONIUM TEXTURE & ZIRCALOY-4 TEXTURE \\
\hline As-received (1.55mm) & $\begin{array}{l}\{11 \overline{2} 2\}\langle 10 \overline{1} 0\rangle \text { and } \\
\text { near to } \\
\{10 \overline{1} 1\}\langle 11 \overline{2} 0\rangle\end{array}$ & $\begin{array}{c}\{11 \overline{2} 2\} \text { fiber and } \\
\text { near to } \\
\{0001\}\langle 11 \overline{2} 0\rangle\end{array}$ \\
\hline Rolled (0.70mm) & $\{11 \overline{2} 2\}$ fiber & $\begin{array}{l}\{11 \overline{2} 2\}\langle 10 \overline{1} 0\rangle \text { and } \\
\text { weak }\{11 \overline{2} 2\} \text { fiber }\end{array}$ \\
\hline Rolled at $500^{\circ} \mathrm{C}$ & $\{11 \overline{2} 2\}\langle 10 \overline{1} 0\rangle$ & $\begin{array}{l}\{11 \overline{2} 2\}\langle 10 \overline{1} 0\rangle \text { and } \\
\text { weak }\{11 \overline{2} 2\} \text { fiber }\end{array}$ \\
\hline Annealed at $600^{\circ} \mathrm{C}$ & $\begin{array}{c}\{11 \overline{2} 2\}\langle 10 \overline{1} 0\rangle \text { and } \\
\text { near to } \\
\{10 \overline{1} 1\}\langle 11 \overline{2} 0\rangle\end{array}$ & $\begin{array}{c}\qquad\{1 \overline{2} 2\} \text { fiber and } \\
\text { weak tendency to }\{0001\}\langle 11 \overline{2} 0\rangle\end{array}$ \\
\hline
\end{tabular}

Figures 3 and 4 present the hardness increment due to plastic deformation produced by rolling in both materials at room temperature $\left(20^{\circ} \mathrm{C}\right)$ and $500^{\circ} \mathrm{C}$, respectively.

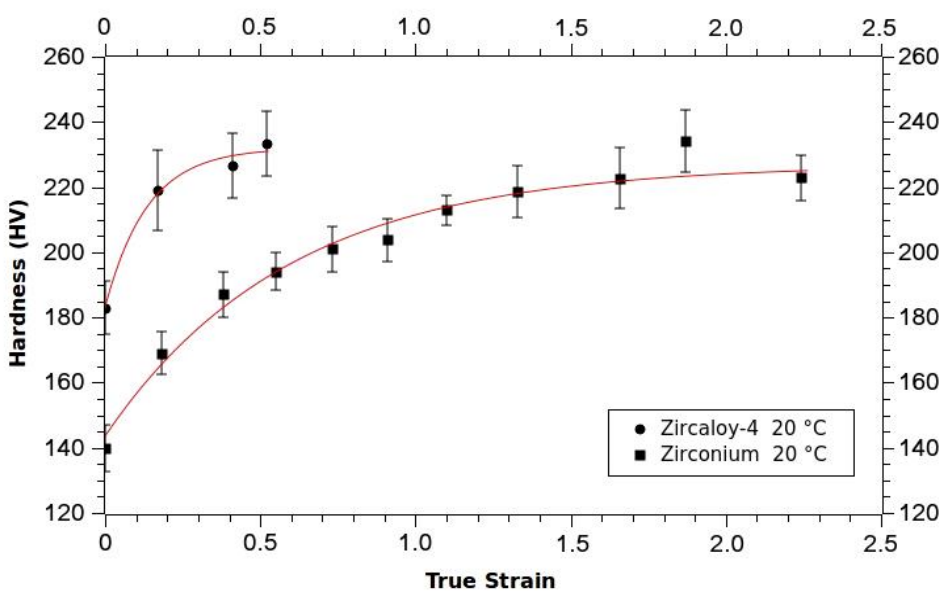

Figure 3: Variation of hardness with rolling deformation at room temperature for pure zirconium and zircaloy-4. 


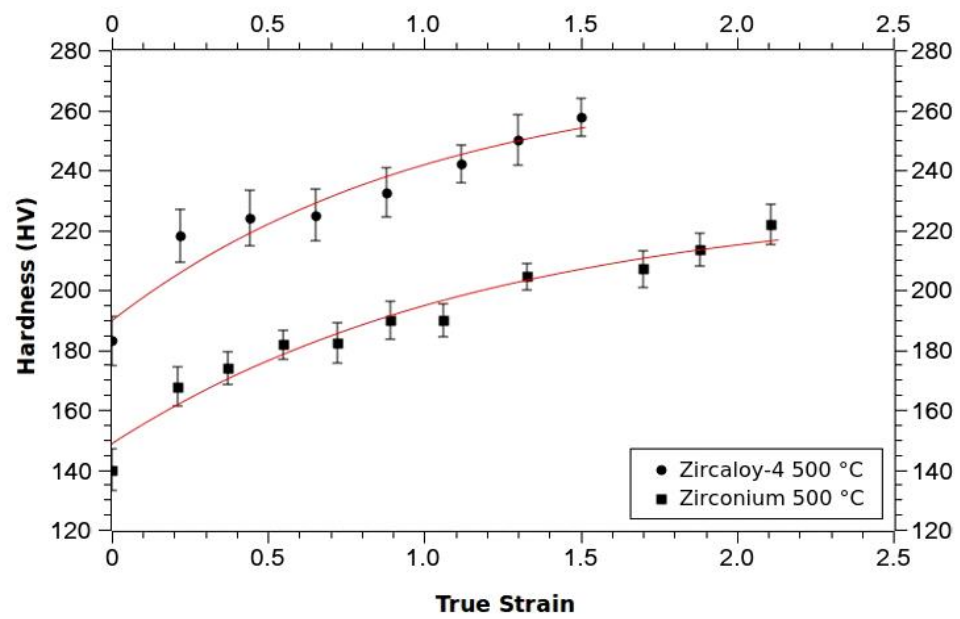

Figure 4: Variation of hardness with rolling deformation at $500^{\circ} \mathrm{C}$ for pure zirconium and zircaloy-4.

The increase in ductility for an increasing deformation temperature observed in Figures 2 to 4 has three main causes: increase in the number of slip systems, the occurrence of dislocation cross-slip and the usual increase in dislocation mobility. In addition, Zry-4 showed higher strain hardening than pure zirconium. The effect of tin, lowering the zirconium stacking fault energy [21,22], may have contributed to this behavior. The thickness reductions and annealing conditions adopted for the two materials $\left(625^{\circ} \mathrm{C}-1 \mathrm{hr}\right.$ for pure $\mathrm{Zr}$ and $725^{\circ} \mathrm{C}-1 \mathrm{hr}$ for Zry-4) yielded strips of the same thickness $(1.55 \mathrm{~mm})$ and with a similar average diameter $(10 \mu \mathrm{m})$ of equiaxed recrystallized grains.

\subsection{Static recovery and recrystallization}

For the static recrystallization studies, samples of the two materials with equalized microstructures and average grain size of approximately $10 \mu \mathrm{m}$ in average diameter were cold rolled to a thickness reduction of $55 \%$. The cold rolled strips were then annealed for one hour between 450 e $600^{\circ} \mathrm{C}$. The isochronous softening curves of these samples are shown in Figure 5.

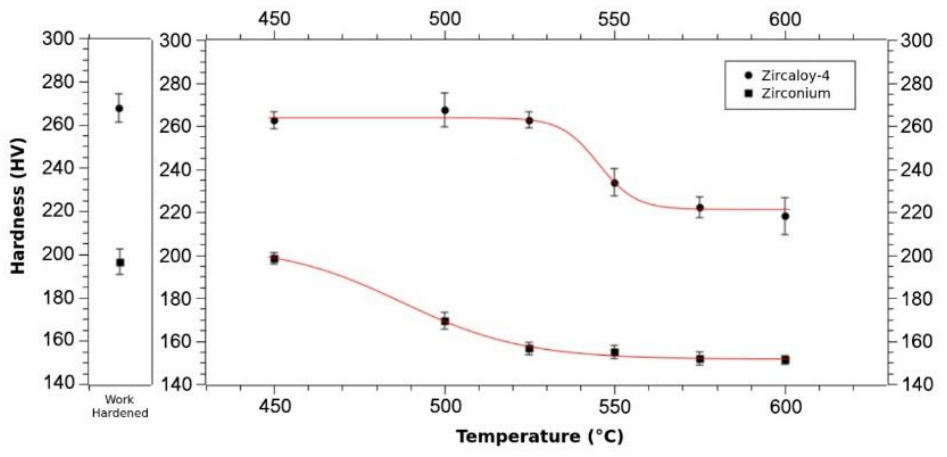

Figure 5: Variation of hardness as a function of annealing temperature (annealing time: 1 hour) in cold rolled strips (thickness reduction of 55\%) of pure zirconium and zircaloy-4.

The two curves in Figure 5 show that the softening curve of the alloy is displaced to higher temperatures compared to pure zirconium. Also, the hardness drop of pure zirconium is less pronounced. In Figure 6, the softening curves of both materials and their respective derivative curves are also presented. The derivative curve of Zry-4 is narrower in comparison with pure $\mathrm{Zr}$ and its minimum, i.e., the maximum softening rate, is shifted to higher temperatures by about $60^{\circ} \mathrm{C}$. 

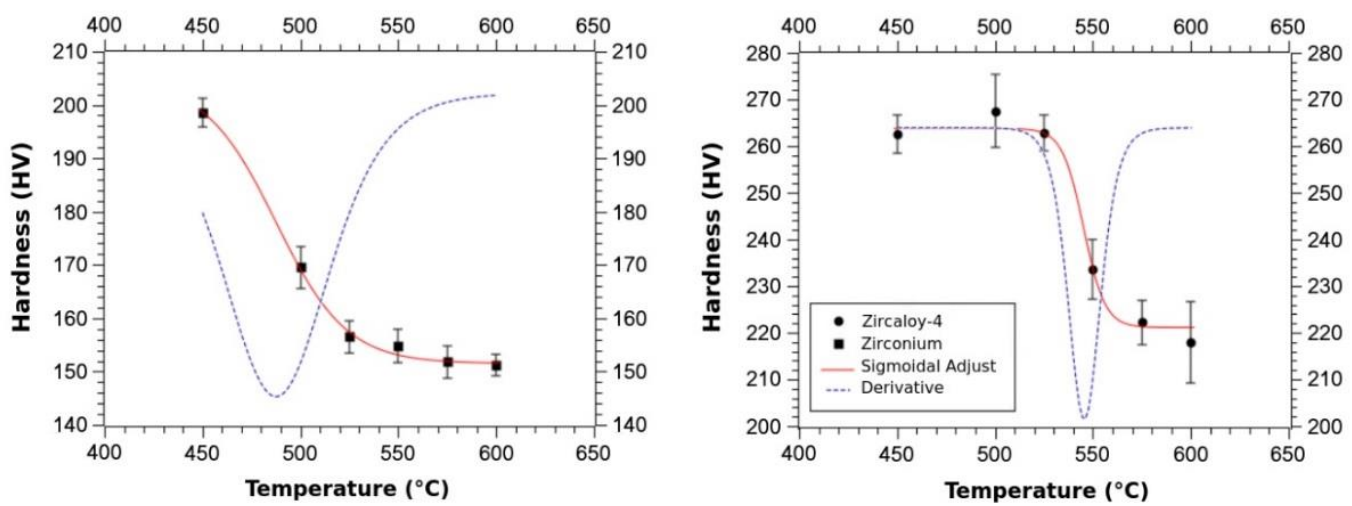

Figure 6: Isochronous softening curves (hardness versus annealing temperature) for pure zirconium and zircaloy-4 with the respective derivative curves.

The higher resistance to recrystallization found in the alloy is not surprising and can be deduced from the results of literature by comparing existing studies for pure zirconium [8-10] with those on zircaloy-4 $[11,12,13,14,15]$. On the other hand, a more precise comparison between the two materials was not possible from the literature analysis, since the initial microstructures and the deformation and annealing parameters used in those works were very dissimilar.

The behavior of the curves in Figures 5 and 6 suggests that, while pure zirconium softens by recovery and recrystallization, the relative contribution of recovery is less pronounced in the alloy. The interaction of solute atoms with dislocations, making difficult their rearrangement during annealing, explains the lower contribution of the recovery processes in the softening of the alloy. On the other hand, the interaction of solute atoms and precipitates with migrating grain boundaries explains the need of greater thermal activation for the occurrence of recrystallization in the alloy.

Subsequently, recrystallization textures were also studied. One-hour annealing at 550 and $575^{\circ} \mathrm{C}$ after cold rolling was enough to cause static recrystallization in both materials, pure $\mathrm{Zr}$ and Zry-4. The crystallographic orientation of the basal planes, however, remained stable (see Table 1). At $600^{\circ} \mathrm{C}$, a change in this direction was observed in Zry-4, tending to $\{0002\}<1100\rangle$, while in pure zirconium basal planes remain stable. Zirconium and alloys have a very stable texture, and recrystallization is not enough to change it. Finally, the texture evolution during mechanical and thermal processing observed in this work is in reasonable agreement with the literature about zirconium alloy crystallographic texture $[16,23,24]$.

\section{CONCLUSIONS}

The following conclusions can be drawn:

- Pure Zr and Zry-4 in the as-received condition show a monophasic ( $\alpha$-phase) microstructure, but with completely different features. Pure Zr displays a microstructure of equiaxed recrystallized grains, while the alloy Zry-4 displays a basketweave microstructure, typical of zirconium alloys quenched from the $\beta$ phase.

- At room temperature, pure $\mathrm{Zr}$ shows appropriate plasticity, but the alloy has low ductility. Above $300^{\circ} \mathrm{C}$, the ductility of both materials increases significantly with an increase in rolling temperatures up to $500^{\circ} \mathrm{C}$. This increase in ductility has three main causes: enhanced number of slip systems, the occurrence of crossslip and increase in the mobility of dislocations.

- During annealing after cold-rolling with a thickness reduction of $55 \%, \mathrm{Zr}$ and Zry-4 softens by recovery and recrystallization, but the relative contribution of recovery is less pronounced for the alloy. The interaction of solute atoms with dislocations explains the smaller contribution of the recovery processes to the softening of the alloy. The Zry-4 recrystallization temperature increases by about $60^{\circ} \mathrm{C}$. The interaction of solute atoms and precipitates with migrating grain boundaries explains the need of greater thermal activation for the occurrence of recrystallization in the alloy. 
- The cold rolled texture of both materials shows the predominant component $\{11 \overline{2} 2\}\langle 10 \overline{1} 0\rangle$. After recrystallization, the crystallographic orientation of the basal planes, however, remains stable. After annealing at $600^{\circ} \mathrm{C}$, in Zry-4 the texture changes to $\{0002\}\langle 1100\rangle$, while in pure zirconium basal planes orientations remain stable.

\section{ACKNOWLEDGEMENTS}

This research was supported by the Conselho Nacional de Desenvolvimento Científico e Tecnológico (CNPq, Brazil) and by the Centro Tecnológico da Marinha em São Paulo (CTMSP, Brazil). The authors would like to thank Dr. Marcelo Martorano and Dr. Ronald Lesley Plaut for revising this manuscript. The valuable comments of the anonymous reviewers are also highly appreciated.

\section{BIBLIOGRAPHY}

[1] FROES, F.H., YAU, T-L., WEIDINGER, H.G., "Titanium, zirconium and hafnium", In: Cahn, R.W., Haasen, P., Kramer, E.J. (eds.), Structure and Properties of Nonferrous Alloys, v. 8, Chapter 8, pp. 399-468, New York, USA, Wiley-VCH, 1996.

[2] LEMAIGNAN, C., MOTTA, A.T. "Zirconium alloys in nuclear applications". In: Cahn, R.W., Haasen, P., Kramer, E.J. (eds.), Nuclear Materials, v. 10B, chapter 7, pp. 1-51, New York, USA, Wiley-VCH, 1994.

[3] NORTHWOOD, D.O., "The development and applications of zirconium alloys", Materials \& Design, v. 6, p. 58-70, 1985.

[4] XU, L., XIAO, Y., VAN SANDWIJK, A., et al., "Production of nuclear grade zirconium: A review", Journal of Nuclear Materials, v. 466, pp. 21-28, 2015.

[5] TRICOT, R., "The metallurgy and functional properties of hafnium (Review article)", Journal of Nuclear Materials, v. 189, pp. 277-288, 1992.

[6] GOLDEN, L.B., LANE, I.R., ACHERMAN, W.L., "Corrosion resistance of titanium, zirconium and stainless steel”, Industrial \& Chemical Engineering, v. 44, pp. 1930-1939, 1952.

[7] CHEADLE, B.A., Fabrication of zirconium alloys into components for nuclear reactors, Lowe Jr., A.L., Parry, G.W. (eds.), ASTM STP 633: Zirconium in the nuclear industry, pp. 457-485, American Society for Testing Materials (ASTM), USA, pp. 457-485, 1977.

[8] DUNKERLEY, F.J., PLEDGER, F., DAMIANO, V., et al., "Grain growth and recrystallization characteristics of zirconium", Journal of Metals, v. 191, pp. 1003-1008, 1951.

[9] DESALVO, A., ZIGNANI, F., "Electrical resistivity of recovery phenomena in cold-worked zirconium" Journal of Nuclear Materials, v. 20, pp. 108-118, 1966.

[10] CHAUBET, D., FONDÉRE, J.P., BACROIX, B., "Strain-anneal growth of Zr 701 large crystals", Materials Science and Engineering A., v. 300, pp. 245-253, 2001.

[11] HUNT, C.E.L., SCHULSON, E.M., "Recrystallization of zircaloy-4 during transient heating", Journal of Nuclear Materials, v. 92: pp. 184-190, 1980.

[12] MUNTASEL, J., NAVARRO J., CESARI, E., et al., "Recovery and recrystallization of zircaloy-4", Thermochimica Acta, v. 87: pp. 169-176, 1985.

[13] DUNLOP, J.W.C., BRÉCHET, Y.J.M., LEGRAS L., et al., "Modelling isothermal and non-isothermal recrystallisation kinetics: application to Zircaloy-4", Journal of Nuclear Materials, v. 366, pp.178-186, 2007.

[14] CHAKRAVARTTY, J.K., KAPOOR, R., SARKAR, A., et al., "Dynamic recrystallization in zirconium alloys", Journal of ASTM International, v. 7, pp. 1-17, 2010.

[15] KUMAR, G., SINGH, R., SINGH, J., et al., "Defining the stages of annealing in a moderately deformed commercial Zirconium alloy", Journal of Nuclear Materials, v. 466, pp. 243-252, 2015.

[16] ZHU, K.Y., CHAUBET, D., BACROIX, B.F., et al., "A study of recovery and primary recrystallization mechanisms in a Zr-2Hf alloy", Acta Materialia, v. 53, pp. 5131-5140, 2005.

[17] KAD, B.K., GEBERT J-M., PEREZ-PRADO, M.T., et al., "Ultrafine-grain-sized zirconium by dynamic deformation", Acta Materialia, v. 54, pp. 4111-4127, 2006.

[18] LEE, B.S., KIMA, M.H., WANG, S.K., et al., "Grain refinement of commercially pure zirconium by 
ECAP and subsequent intermediate heat treatment", Materials Science and Engineering A, v. 449-451, pp. 1087-1089, 2007.

[19] ZIMMERMANN, A.J.O., Encruamento, recristalização e textura cristalográfica de zircônio puro e da liga zircaloy-4, Tese de D. Sc., Escola Politécnica da Universidade de São Paulo (EPUSP), São Paulo, SP, Brasil, 2014.

[20] MONNET, G., DEVINCRE, B., KUBIN, L.P., "Dislocation study of prismatic slip systems and their interactions in hexagonal close packed metals: application to zirconium”, Acta Materialia, v. 52, pp. 43174328, 2004.

[21] SASTRY, D.H., LUTON, M.J., JONAS, J.J., Stacking fault energy and its influence on hightemperature plastic flow in Zr-Sn alloys”, Philosophical Magazine, v. 30, pp. 115-127, 1974.

[22] UDAGAWA, Y., YAMAGUCHI, M., TSURU, T., et al., "Effect of Sn and Nb on generalized stacking fault energy surfaces in zirconium and gamma hydride habit planes", Philosophical Magazine, v. 91, pp. 1665-1678, 2011.

[23] WANG, Y.N., HUANG, J.C., "Texture analysis in hexagonal materials", Materials Chemistry and Physics, v. 81, pp. 11-26, 2003.

[24] GERSPACH, F., BOZZOLO, N., WAGNER, F., “About texture stability during primary recrystallization of cold-rolled low alloy zirconium”, Scripta Materialia, v. 60, pp. 203-206, 2009.

\section{ORCID}

Angelo José de Oliveira Zimmermann https://orcid.org/0000-0003-3692-2325

Angelo Fernando Padilha é

https://orcid.org/0000-0002-5494-9137 